\title{
Interactions of Gaseous $\mathrm{HNO}_{3}$ and Water with Individual and Mixed Alkyl Self-Assembled Monolayers at Room Temperature
}

\author{
Noriko Nishino ${ }^{1}$, Scott A. Hollingsworth ${ }^{2}$, Abraham C. Stern ${ }^{1}$, Martina Roeselová ${ }^{3}$, Douglas \\ J. Tobias ${ }^{1, *}$, and Barbara J. Finlayson-Pitts ${ }^{1, *}$ \\ ${ }^{1}$ Department of Chemistry, University of California, Irvine, California, 92697-2025, USA \\ ${ }^{2}$ Department of Molecular Biology and Biochemistry, University of California Irvine, CA, \\ 92697-2025, USA \\ ${ }^{3}$ Institute of Organic Chemistry and Biochemistry, Academy of Sciences of the Czech Republic, \\ Flemingovo nam. 2, 16610 Prague 6, Czech Republic
}

\begin{abstract}
The major removal processes for gaseous nitric acid $\left(\mathrm{HNO}_{3}\right)$ in the atmosphere are dry and wet deposition onto various surfaces. The surface in the boundary layer is often covered with organic films, but the interaction of gaseous $\mathrm{HNO}_{3}$ with them is not well understood. To better understand the factors controlling the uptake of gaseous nitric acid and its dissociation in organic films, studies were carried out using single component and mixtures of C8 and C18 alkyl self-assembled monolayers (SAMs) attached to a germanium (Ge) attenuated total reflectance (ATR) crystal upon which a thin layer of $\mathrm{SiO}_{\mathrm{x}}$ had been deposited. For comparison, diffuse reflectance infrared Fourier transform spectrometry (DRIFTS) studies were also carried out using a C18 SAM attached to the native oxide layer on the surface of silicon powder. These studies show that the alkyl chain length and order/disorder of the SAMs does not significantly affect the uptake or dissociation/ recombination of molecular $\mathrm{HNO}_{3}$. Thus, independent of the nature of the $\mathrm{SAM}$, molecular $\mathrm{HNO}_{3}$ is observed up to 70-90\% relative humidity. After dissociation, molecular $\mathrm{HNO}_{3}$ is regenerated on all SAM surfaces when water is removed. Results of molecular dynamics simulations are consistent with experiments and show that defects and pores on the surfaces control the uptake, dissociation and recombination of molecular $\mathrm{HNO}_{3}$. Organic films on surfaces in the boundary layer will certainly be more irregular and less ordered than SAMs studied here, therefore undissociated $\mathrm{HNO}_{3}$ may be present on surfaces in the boundary layer to a greater extent than previously thought. The combination of this observation with the results of recent studies showing enhanced photolysis of nitric acid on surfaces suggests that renoxification of deposited nitric acid may need to be taken into account in atmospheric models.
\end{abstract}

\section{Introduction}

Nitric acid $\left(\mathrm{HNO}_{3}\right)$ is formed through atmospheric oxidation of oxides of nitrogen $\left(\mathrm{NO}_{\mathrm{x}}=\right.$ $\mathrm{NO}+\mathrm{NO}_{2}$ ) such as the reaction of $\mathrm{NO}_{2}$ with hydroxyl radicals and the reactions of nitrate

*Authors to whom correspondence should be addressed: experimental studies, bjfinlay@uci.edu; 949-824-7670; theory, dtobias@uci.edu; 949-824-4295. 
radicals with certain organics, e.g., aldehydes. ${ }^{1}$ The removal processes for gas-phase $\mathrm{HNO}_{3}$ in the atmosphere are primarily through dry and wet deposition, and these processes are in general considered as sinks for $\mathrm{NO}_{\mathrm{x}} \cdot{ }^{1}$ However, recent studies have shown that renoxification of $\mathrm{HNO}_{3}$ occurs on surfaces and releases $\mathrm{NO}_{\mathrm{y}}$ (i.e., $\mathrm{HONO}, \mathrm{NO}_{2}$ ) back into air. Heterogeneous photochemistry of nitrate ions formed on oxide surfaces (e.g., $\mathrm{Al}_{2} \mathrm{O}_{3}$ ) by adsorption of $\mathrm{HNO}_{3}$ also generates $\mathrm{NO}_{\mathrm{y}} \cdot{ }^{2-5}$, These processes suggest the potential importance of heterogeneous reactions/interactions of gaseous $\mathrm{HNO}_{3}$ on surfaces. ${ }^{4,}$, ${ }^{-12}$ Of particular significance are studies showing enhanced photochemistry of nitric acid on surfaces compared to the gas phase. ${ }^{8,11,13,14}$

Surfaces in the boundary layer are often covered by a variety of organic films that can change surface properties. ${ }^{15-19}$ However, it is not well understood how organic films interact with gaseous $\mathrm{HNO}_{3}$. A recent combined experimental/theoretical study by Moussa et al. ${ }^{20}$ investigated interactions of gas-phase $\mathrm{HNO}_{3}$ and water on organic films using a $\mathrm{C} 8$ alkene terminated self-assembled monolayer (SAM) as a model system. SAMs are relatively well-defined molecular assemblies with strong van der Waals interactions between alkyl chains, leading to the formation of highly ordered and tightly packed monolayers. ${ }^{21,22}$ These earlier studies ${ }^{20}$ focused on the alkene SAM formed by reacting 7octenyltrichlorosilane $\left[\mathrm{H}_{2} \mathrm{C}=\mathrm{CH}\left(\mathrm{CH}_{2}\right)_{6} \mathrm{SiCl}_{3}\right]$ (referred to as " $\mathrm{C} 8=$ " hereafter) with a thin layer of silicon oxide $\left(\mathrm{SiO}_{\mathrm{x}}\right)$ on a germanium $(\mathrm{Ge})$ attenuated total reflectance (ATR) crystal. The uptake and nature of $\mathrm{HNO}_{3}$, i.e. molecular or dissociated, were studied using ATR-FTIR measurements of the organic film during exposure to gas phase $\mathrm{HNO}_{3}$ and water vapor. Surprisingly, adsorbed $\mathrm{HNO}_{3}$ on the SAM was observed to be retained in part in its molecular form when water vapor was added at concentrations equivalent to a relative humidity (RH) as high as $70 \%$, while it completely dissociated at $20 \% \mathrm{RH}$ on a surface without a SAM. Molecular dynamics simulations showed that $\mathrm{HNO}_{3}$ intercalates into defects between alkyl chains, resulting in the acid being protected from dissociation by water vapor. This suggests that nitric acid may also be sequestered in irregular SAM monolayers consisting of mixtures of chains of significantly different lengths, where pockets could be formed above the shorter chains and serve the same role as defects in the SAM coating.

We report here such studies using SAMs with C18 and C8 alkyl chains respectively, as well as a mixture of the two. The goal was to create a less regular arrangement of the SAM and to examine how this affects the trapping of $\mathrm{HNO}_{3}$ and the dissociation/recombination induced by water vapor. Such films are expected to be more representative of disordered organic surface films on surfaces in the tropospheric boundary layer. ATR-FTIR experimental studies and molecular dynamics simulations are combined to provide insight into the nature of the binding of nitric acid in disordered films and the accessibility of the acid to gas phase water.

\section{Experimental}

\section{ATR-FTIR Measurements of Surface Species}

Surface species associated with SAMs were monitored using an ATR accessory (Pike Technologies, Madison, WI) located in the sampling compartment of an FTIR spectrometer 
(Mattson Galaxy 5020, now Thermo Electron Corp., Madison, WI). Experimental methods follow those described in the previous study. ${ }^{20}$ A germanium ATR crystal $(8 \mathrm{~cm} \times 1 \mathrm{~cm} \times$ $0.4 \mathrm{~cm}$, Pike Technologies, Madison, WI) was placed on a horizontal ATR holder such that the incoming infrared beam strikes the crystal at $45^{\circ}$ angle of incidence and undergoes 10 total internal reflections along its length. A thin $(20 \mathrm{~nm})$ film of $\mathrm{SiO}_{\mathrm{x}}$ to which the $\mathrm{SAMs}$ would be attached was deposited on the topside surface $(8 \mathrm{~cm} \times 1 \mathrm{~cm})$ of the ATR crystal by plasma-enhanced chemical vapor deposition. The calculated depth of penetration ${ }^{23}$ of the evanescent wave was $0.6-3.0 \mu \mathrm{m}$ over the range from $4000-800 \mathrm{~cm}^{-1}$, allowing for the $\mathrm{SAM}(\sim 2.5 \mathrm{~nm} \text { thickness for } \mathrm{C} 18 \mathrm{SAM})^{24,25}$ and adsorbed species to be interrogated. The topside surface was enclosed in a $\sim 1 \mathrm{~cm}^{3}$ volume cell consisting of inlet and outlet ports to provide a continuous flow of gases over the $\mathrm{SAM} / \mathrm{SiO}_{\mathrm{x}}$ surface. The interior walls of the cell were coated with halocarbon wax (Halocarbon Products Corporation, River Edge, NJ) to prevent corrosion by $\mathrm{HNO}_{3}$. Single beam spectra before, during, and after the reaction were collected by averaging 512 scans at $2 \mathrm{~cm}^{-1}$ resolution.

Before coating with SAMs, the $\mathrm{SiO}_{\mathrm{X}} / \mathrm{Ge}$ crystal was sonicated with purified water (Milli-Q Plus, $18.2 \mathrm{M} \Omega \mathrm{cm}$ ) for $15 \mathrm{~min}$, boiled in ethanol and then dichloromethane, and plasma cleaned with an argon (UHP, >99.999\%, Oxygen Services Co.) plasma discharge at low RF for 20 min (Plasma Cleaner Sterilizer PDC-32G, Harrick Scientific Products, Inc., Ossining, New York). To create the SAMs, the $\mathrm{SiO}_{\mathrm{x}}$ on a Ge ATR crystal was exposed to a $2 \mathrm{mM}$ solution of n-octyltrichlorosilane $\left[\mathrm{CH}_{3}\left(\mathrm{CH}_{2}\right)_{7} \mathrm{SiCl}_{3}\right]$ and/or octadecyl trichlorosilane $\left[\mathrm{CH}_{3}\left(\mathrm{CH}_{2}\right)_{17} \mathrm{SiCl}_{3}\right]$ (<3\% $\mathrm{C} 18$ isomers) (both from Gelest Inc.) in hexadecane (ReagentPlus ${ }^{\circledR} 99 \%$, Sigma-Aldrich) for 45 min twice. These SAMs are referred to as "C8" and "C18", respectively, in the following discussion. As described previously, 20, 21, 24 SAMs were created on $\mathrm{SiO}_{\mathrm{x}}$ surfaces via reactions of the trichlorosilane terminal functionality with surface silanol groups. The crystal was then boiled in dichloromethane twice to remove unreacted silanes.

Exposure to gaseous $\mathrm{HNO}_{3}$ was performed by flowing dry $\mathrm{N}_{2}$ (UHP, $99.999 \%$, Praxair, Danbury, CT) over a 1:3 (v/v) solution of $\mathrm{HNO}_{3}\left(70 \mathrm{wt} \% \mathrm{HNO}_{3} 99.999+\%\right.$, Sigma Aldrich) with $\mathrm{H}_{2} \mathrm{SO}_{4}\left(>95 \%\right.$ wt $\%$, Fluka) in a glass trap at $20 \mathrm{~mL} \mathrm{~min}^{-1}$. The $\mathrm{HNO}_{3}$ flow was then combined with $200 \mathrm{~mL} \mathrm{~min}^{-1}$ of dry or humid $\mathrm{N}_{2}$ to give a total flow of $220 \mathrm{~mL} \mathrm{~min}^{-1}$, where $\sim 70 \mathrm{~mL} \mathrm{~min}^{-1}$, was diverted into the reaction cell and the rest vented to a hood. For the experiments in the presence of water vapor, humidified air was generated by passing $\mathrm{N}_{2}$ through two bubblers containing purified water and diluted with dry $\mathrm{N}_{2}$ to achieve the desired relative humidity $(\mathrm{RH})$. The surface was purged overnight with dry $\mathrm{N}_{2}$ before experiments. All experiments were conducted at atmospheric pressure and room temperature $(295 \pm 2 \mathrm{~K})$.

\section{DRIFTS Measurements of Surface Species}

For comparison to the ATR-FTIR results, a limited set of diffuse reflectance infrared Fourier transform spectrometry (DRIFTS) experiments were also conducted using silicon ( $\mathrm{Si}$ ) powder (60 mesh, $99.999 \%$ trace metal basis, Sigma-Aldrich, used as received) with and without a SAM coating. Single beam DRIFTS spectra of bare Si powder without SAM (not 
shown) showed peaks due to $\mathrm{C}-\mathrm{H}$ stretches at 2858,2928 and $2963 \mathrm{~cm}^{-1}$, indicating the presence of some organic contaminants on the surface. ${ }^{26}$

The C18 SAM was chosen for these studies as it is expected to form the least disordered monolayer. Silicon is known to have a thin layer of $\mathrm{SiO}_{\mathrm{x}}{ }^{27,} 28$ to which the SAM was attached. The $\mathrm{SiO}_{\mathrm{x}}$ layer on $\mathrm{Si}$ is typically quite irregular, having obvious pores and defects. ${ }^{27}$ The $\mathrm{C} 18$ SAM was created by sonicating and stirring $\sim 0.4 \mathrm{~g}$ Si powder with a 4 $\mathrm{mM}$ solution of octadecyl trichlorosilane in $16 \mathrm{~mL}$ benzene (ACS reagent $\mathbf{2 9} .0 \%$, SigmaAldrich) for an hour two times sequentially. The coated Si powder was then filtered, sonicated with dichloromethane twice and dried. Infrared spectra of the C18 SAM on $\mathrm{Si}$ powder show no peaks due to benzene after drying. The Brunauer-Emmett-Teller (BET) surface areas of the Si powder with and without the C18 SAM were measured using nitrogen adsorption with an Autosorb®-1 Surface Area Analyzer (Quantachrome Instruments, Boynton Beach, FL) to be within experimental error of each other, $6.9 \pm 0.1$ and $7.0 \pm 0.6$ $\mathrm{m}^{2} \mathrm{~g}^{-1}(1 \sigma)$, respectively.

The DRIFTS system consists of a Harrick Scientific vacuum reaction cell (Model HVCDR2) and a diffuse reflectance attachment (Model DRA-2CS) situated in a sampling compartment of a FTIR spectrometer (Mattson, RS 10000, now Thermo Electron Corp., Madison, WI). The DRIFTS apparatus is described elsewhere. ${ }^{29,30}$ Briefly, the reaction cell contained an internal sample cup $(1.1 \mathrm{~cm}$ in diameter and $0.3 \mathrm{~cm}$ in depth) in the center of the cell into which $0.3 \mathrm{~g}$ Si powder was tightly pressed. ZnSe windows were located on the reaction cell to transmit the IR beam to the solid sample where diffuse reflection occurs, and then to the detector. The cell had an inlet port at the side of the cell housing through which gases were added, and an outlet port at the side of the sample cup for pumping the gas mixtures through the sample at $\sim 100 \mathrm{~mL} \mathrm{~min}^{-1}$. The $\mathrm{HNO}_{3}$ flows in dry $\mathrm{N}_{2}$ or humidified $\mathrm{N}_{2}$ were created as described above in the ATR-FTIR experimental section, with a total flow of $220 \mathrm{~mL} \mathrm{~min}^{-1}$, and the excess flow $\left(\sim 120 \mathrm{~mL} \mathrm{~min}^{-1}\right)$ diverted to a vent. The interior walls of the cell and $\mathrm{ZnSe}$ windows were coated with halocarbon wax to prevent corrosion. The reaction cell with the sample in place was purged overnight with dry $\mathrm{N}_{2}$ before experiments. The single beam DRIFTS spectra before, during, and after the reaction were collected by averaging 512 scans at $2 \mathrm{~cm}^{-1}$ resolution.

\section{Molecular Dynamics (MD) Simulations}

Three self-assembled monolayers of varied compositions were modeled on an ordered lattice of $\mathrm{SiO}_{2}$, which as previous work has shown is a reasonable facsimile for the amorphous $\mathrm{SiO}_{2}$ surface to which the SAMs bind. ${ }^{31}$ The substrate of the monolayer, modeled here as the alpha-tridymite form of $\mathrm{SiO}_{2},{ }^{32}$ measured $78.66 \times 75.60 \times 14.00 \AA$, or $15 \times 18 \times 2$ unit cells. The SAM systems constructed were: (1) a C8 system made from octyltrihydroxysilane $\left[\mathrm{CH}_{3}\left(\mathrm{CH}_{2}\right)_{7} \mathrm{Si}(\mathrm{OH})_{3}\right],(2)$ a $\mathrm{C} 18$ system made from octadecyl trihydroxysilane $\left[\mathrm{CH}_{3}\left(\mathrm{CH}_{2}\right)_{17} \mathrm{Si}(\mathrm{OH})_{3}\right]$, and (3) a 1:1 mixture of $\mathrm{C} 8$ and $\mathrm{C} 18$ molecules distributed randomly. The siloxanes were covalently bonded to one surface of the $\mathrm{SiO}_{2}$ substrate via dehydration through one of the hydroxyls of the head group (removing one terminal oxygen and two hydrogen atoms). In order to maintain charge neutrality of the simulation cell, half 
of the $\mathrm{Si}$ atoms of the opposite surface of the $\mathrm{SiO}_{2}$ slab were removed. Note that the opposite surface of the $\mathrm{SiO}_{2}$ slab was not chemically capped with $\mathrm{H}$ atoms.

Defects were created in the monolayers by removing four individual alkylsiloxane molecules, approximately equidistant from each other and replacing each with a free hydroxyl group (Figure 1). The defect configuration was identical in all three systems. A single nitric acid molecule was then placed in the vacuum of the simulation cell ( $4 \AA$ above the SAM) and allowed to equilibrate for $10 \mathrm{~ns}$. Once the nitric acid was observed to be buried in the defect, an additional $10 \mathrm{~ns}$ of simulation was carried out to investigate whether the acid molecule would leave the defect or remain buried. At this point, the simulations were continued with the inclusion of between one to eight water molecules in the vapor above the SAM surface to approximate the effect of increasing relative humidity. This approach is reasonable given that only one or two water molecules would be expected to be present in humid air of an equal volume to the simulated cell. ${ }^{33}$ The systems were allowed to equilibrate for $10 \mathrm{~ns}$. This was followed by a second $5 \mathrm{~ns}$ trajectory which was generated for analysis.

During the simulation, several constraints and external forces were used to model the system. A $1.0 \mathrm{kcal} / \mathrm{mol} / \AA^{2}$ constraint was placed on the positions of all atoms in the $\mathrm{SiO}_{2}$ substrate in addition to the terminal $\mathrm{O}$ and $\mathrm{Si}$ atoms of the alkylsiloxane chains. Because only one surface of the $\mathrm{SiO}_{2}$ slab was covered by the SAM, a reflective wall potential located at $\mathrm{z}=90 \AA$ was used to prevent molecules in the vapor from interacting with the unsaturated $\mathrm{SiO}_{2}$ surface through periodic boundary conditions. Although the reflective wall prevents the molecules themselves from diffusing across the boundary, intermolecular interactions can still extend through the periodic boundary. Thus, an additional layer of vacuum was included by extending the simulation cell by $30 \AA$ along the $\mathrm{z}$-axis to ensure that such interactions were negligible. The resulting unit cell for the simulations was $78.66 \times$ $75.60 \times 120 \AA$. Because our model explicitly included an inherently anisotropic solid substrate, which possessed a permanent dipole, the standard 3D Ewald summation techniques utilizing the conducting boundary condition could not be used directly. An alternative would be to perform the summation in two dimensions, but this is computationally inefficient. Instead, we employed a correction term to both the forces and the electrostatic potential which accounted for the lack of periodicity in the $\mathrm{z}$ dimension and the permanent dipole moment of the system. ${ }^{34}$ The alkylsiloxane force field parameters were adapted from the CHARMM27 force field which has been successfully applied to MD simulations of alkylthiolate SAMs on gold. ${ }^{20,35,36}$ The parameters for the solid $\mathrm{SiO}_{2}$ crystal were taken from the work of Stevens et al. ${ }^{31}$ Water molecules were modeled using TIP3P parameters, ${ }^{37}$ while the nitric acid force field parameters were identical to those used in previous work..$^{20,35,36}$ The simulations were carried out using the NAMD 2.7 software package. ${ }^{38}$ 


\section{Results and discussion}

\section{A. Infrared studies of interactions of gaseous $\mathrm{HNO}_{3}$ and water vapor with self-assembled monolayers}

The degree of ordering in SAMs can be estimated by the peak position and the width of the $\mathrm{CH}_{2}$ stretches in the absorption spectra. ${ }^{24,39}$ Tightly packed alkyl chains typically show the peak absorbances for the $-\mathrm{CH}_{2}$ - asymmetric and symmetric stretches at $2915-2917 \mathrm{~cm}^{-1}$ and $2848-2850 \mathrm{~cm}^{-1}$, respectively. ${ }^{22,39}$ Less ordered alkyl chains in SAMs exhibit peaks at higher frequencies with a larger full width at half maximum (FWHM). Table 1 shows peak frequencies and FWHM for $\mathrm{C} 18, \mathrm{C} 8$, and C8/C18 mixed SAMs prepared on $\mathrm{SiO}_{\mathrm{x}} / \mathrm{Ge}$ ATR crystals, as well as the C18 SAM on Si powder. For comparison, the peak positions and FWHM for ordered SAMs reported in the literature ${ }^{22,39}$ are also shown. The C18 SAM on the $\mathrm{SiO}_{\mathrm{X}} / \mathrm{Ge}$ crystal shows that the film has peak positions and FWHM in excellent agreement with literature values for well-ordered SAMs, ${ }^{22,} 39$ as expected from the strong van der Waals interactions between the long alkyl chains. The C8/C18 mixed SAM on $\mathrm{SiO}_{\mathrm{x}} / \mathrm{Ge}$ appears to be somewhat less ordered. Whether the mixed C8/C18 SAM is a homogeneous blending of the two different alkyl chain lengths or, alternatively, in islands of the two individual components is not known. However, if the morphology consisted of large islands of the components, one might expect the peak positions and FWHM to reflect those of the single component SAMs, which are similar to each other. The fact that the mixed SAM appears to be more disordered suggests significant intermingling of the two chain lengths. This is expected to create some pockets above the shorter chains which could potentially trap gases such as $\mathrm{HNO}_{3}$.

The C18 SAM on silicon powder is the least well ordered, which is not surprising given its irregular surface oxide film. ${ }^{27,} 28$ The $\mathrm{SiO}_{\mathrm{x}}$ thin film on Ge crystals is mechanically controlled during deposition from the gas phase, while the $\mathrm{SiO}_{\mathrm{x}}$ on $\mathrm{Si}$ powder is grown by air oxidation of the surface. In the latter case, images reported by other laboratories of $\mathrm{SiO}_{\mathrm{x}}$ layers taken by a focused ion beam - scanning electron microscope show a quite irregular surface that contains pores and defects. ${ }^{27}$

Figure 2a shows representative changes in the ATR-FTIR spectra of C18 SAM on $\mathrm{SiO}_{\mathrm{x}} / \mathrm{Ge}$ crystal upon exposure to dry $\mathrm{HNO}_{3}$ (red line) followed by added water vapor (pink - brown lines). The spectrum for dry $\mathrm{HNO}_{3}$ exposure (Fig. 2a, red line) is given by $\mathrm{A}=\log S_{0} / S_{1}$ where $S_{1}$ is the single beam spectrum after the exposure to dry $\mathrm{HNO}_{3}$ and $S_{0}$ is that before the exposure. Thus, changes are solely due to the uptake of $\mathrm{HNO}_{3}$. Two prominent peaks appear at $1305 \mathrm{~cm}^{-1}$ and $1670 \mathrm{~cm}^{-1}$ upon exposure to dry $\mathrm{HNO}_{3}$, attributed to symmetric and asymmetric stretches, respectively, of the $\mathrm{NO}_{2}$ group in molecular $\mathrm{HNO}_{3}{ }^{20,40,41} \mathrm{~A}$ broad peak in the $1300-1500 \mathrm{~cm}^{-1}$ region due to nitrate ions $\left(\mathrm{NO}_{3}{ }^{-}\right)$is also present. These peaks were all observed previously for $\mathrm{HNO}_{3}$ with a $\mathrm{C} 8=\mathrm{SAM}^{20}$

When the $\mathrm{HNO}_{3}$ uptake reaches a steady state, water vapor was added incrementally to the $\mathrm{HNO}_{3}$ flow to give relative humidities from $20 \%$ to $90 \%$ (Fig. 2a, pink - brown lines). These spectra $\left(\mathrm{A}=\log S_{0} / S_{1}\right)$ are obtained by taking the ratio of the single beam spectrum scanned after the exposure to $\mathrm{HNO}_{3}$ at various $\mathrm{RH}\left(S_{1}\right)$ to that before the dry $\mathrm{HNO}_{3}$ exposure $\left(S_{0}\right)$. Thus, absorption spectra also represent net changes from the clean SAM 
surface. New peaks at $1620 \mathrm{~cm}^{-1}$ and in the $3000-3500 \mathrm{~cm}^{-1}$ region, the bending and the stretching modes of $\mathrm{H}_{2} \mathrm{O}$, respectively, increase with increasing $\mathrm{RH}$, while the two peaks at 1305 and $1670 \mathrm{~cm}^{-1}$ due to molecular $\mathrm{HNO}_{3}$ decrease. Broad peaks over the range 1300$1500 \mathrm{~cm}^{-1}$ assigned to nitrate ions complexed to water $\left[\mathrm{NO}_{3}^{-}\left(\mathrm{H}_{2} \mathrm{O}\right)_{n}\right]^{42-47}$ also increase. This suggests that molecular $\mathrm{HNO}_{3}$ is dissociated to form nitrate ions in the presence of water vapor. Although the molecular $\mathrm{HNO}_{3}$ peak at $1305 \mathrm{~cm}^{-1}$ is overlapped by the broad absorption due to $\mathrm{NO}_{3}{ }^{-}\left(\mathrm{H}_{2} \mathrm{O}\right)_{n}$, it remains detectable up to $70 \% \mathrm{RH}$. This is consistent with the previous study of Moussa et al. using $\mathrm{C} 8=\mathrm{SAM} .^{20}$

Figure 2b, c shows ATR-FTIR spectra of (b) C8 SAM and (c) C8/C18 mixed SAM on $\mathrm{SiO}_{\mathrm{x}} / \mathrm{Ge}$ upon exposure to dry $\mathrm{HNO}_{3}$ (red lines) followed by the addition of water vapor at 20-90 \% RH (pink - brown lines). Similar to the C18 SAM (Fig. 2a), adsorbed molecular $\mathrm{HNO}_{3}$ at 1670 and $1305 \mathrm{~cm}^{-1}$ as well as nitrate ions over the range $1300-1500 \mathrm{~cm}^{-1}$ appear upon exposure to dry $\mathrm{HNO}_{3}$ (red lines in Fig. $2 \mathrm{~b}, \mathrm{c}$ ). When the water vapor concentration added to the $\mathrm{HNO}_{3}$ flow is incrementally increased, peaks from molecular $\mathrm{HNO}_{3}$ decrease, and those due to $\mathrm{NO}_{3}{ }^{-}\left(\mathrm{H}_{2} \mathrm{O}\right)_{n}$ increase, consistent with increasing dissociation of $\mathrm{HNO}_{3}$. However, in all cases, molecular $\mathrm{HNO}_{3}$ is detected up to $60-70 \% \mathrm{RH}$. When Moussa et al. ${ }^{20}$ conducted a similar exposure of a bare $\mathrm{SiO}_{\mathrm{X}} / \mathrm{Ge}$ surface without $\mathrm{SAMs}$ to $\mathrm{HNO}_{3}$ and water vapor, molecular $\mathrm{HNO}_{3}$ was not observable at $20 \% \mathrm{RH}$. Our results show that $\mathrm{HNO}_{3}$ is retained in its molecular form at higher RH on SAMs regardless of the alkyl chain length and the order/disorder of the SAM. It should be noted that the $-\mathrm{CH}_{2}$ - peaks due to alkyl chains of SAMs are observed on C18 SAM (Fig. 2a) but not on C8 and C8/C18 mixed SAMs (Fig. 2b, c) when water vapor is added. Since $-\mathrm{CH}_{2}$ - peaks from SAMs should not increase solely by adding water vapor, the increase is likely due to perturbation of the tightly packed alkyl chains by water vapor, causing a change in their orientation and order/disorder of the film.

Figures 3a-c show the sequence of spectra when (a) C18 SAM, (b) C8 SAM, and (c) $\mathrm{C} 8 / \mathrm{C} 18$ mixed SAM are dried with a flow of $\mathrm{N}_{2}$ after the exposure to $\mathrm{HNO}_{3}$ and water vapor at $90 \%$ RH. As expected, peaks due to water at $1620 \mathrm{~cm}^{-1}$ and the $3000-3500 \mathrm{~cm}^{-1}$ region (not shown) decrease, indicating that adsorbed water evaporates as the film dries. Peaks due to molecular $\mathrm{HNO}_{3}$ at $1305 \mathrm{~cm}^{-1}$ and $1670 \mathrm{~cm}^{-1}$ reappear, increasing in intensity for the first $30 \mathrm{~min}$. This suggests that nitrate ions and protons recombine to generate molecular $\mathrm{HNO}_{3}$ as water is removed from the surface. Given similar observations in the C8= SAM study of Moussa et al.,${ }^{20}$ this indicates that all SAM surfaces have similar effects on the trapping, dissociation and then regeneration of $\mathrm{HNO}_{3}$ regardless of the alkyl chain length and the order/disorder of the SAM. After the first 30 min of drying, these molecular $\mathrm{HNO}_{3}$ peaks start to decrease as $\mathrm{HNO}_{3}$ evaporates from the film. It is interesting to note that it takes longer to regenerate and evaporate molecular $\mathrm{HNO}_{3}$ on the $\mathrm{C} 8 / \mathrm{C} 18$ mixed SAM, suggesting better trapping on the mixed SAM.

DRIFTS is more sensitive than ATR as a surface probe due to the relatively high surface-tovolume ratio for powders and the increased amount of sample interrogated by the infrared beam. To assess whether this approach might provide more insight into the $\mathrm{HNO}_{3}$-SAM interactions, studies were also carried out using a C18 SAM on Si powder. Figure 4a shows the spectra for this system upon exposure to gasous $\mathrm{HNO}_{3}$ and then water vapor. While 
some peaks are slightly shifted as a result of using different substrates, the results are similar to those using the ATR crystal (Fig. 2a). However, the peak at $1306 \mathrm{~cm}^{-1}$ due to molecular $\mathrm{HNO}_{3}$ is now detected at even higher water vapor concentrations corresponding to $90 \% \mathrm{RH}$. This suggests some enhancement in the trapping of molecular $\mathrm{HNO}_{3}$. Exposure of the silicon powder (Fig. 4b) without a SAM coating to dry $\mathrm{HNO}_{3}$ also showed molecular $\mathrm{HNO}_{3}$ up to $90 \% \mathrm{RH}$ (note that the peak of molecular $\mathrm{HNO}_{3}$ on bare Si powder is slightly shifted from $1306 \mathrm{~cm}^{-1}$ to $1310 \mathrm{~cm}^{-1}$ due to the different substrate). This is in contrast to the observations of Moussa et al. ${ }^{20}$ who observed that addition of water vapor, even at $20 \% \mathrm{RH}$, to nitric acid on a bare $\mathrm{SiO}_{\mathrm{x}} / \mathrm{Ge}$ ATR crystal rendered the $\mathrm{HNO}_{3}$ undetectable. This contrast between the dissociation of $\mathrm{HNO}_{3}$, on a $\mathrm{SiO}_{\mathrm{x}}$ layer deposited on $\mathrm{Ge}$ and on that formed by air oxidation of silicon powder suggests that the irregular powder surface has pores and defects that are more effective in shielding trapped $\mathrm{HNO}_{3}$ from water vapor. Thus, the observation of molecular $\mathrm{HNO}_{3}$ on the $\mathrm{C} 18$ SAM coated silicon powder up to $90 \% \mathrm{RH}$ (Fig. 4a) is likely due in large part to the increased porosity and defects of the irregular powder surface, rather than to enhanced trapping within the less ordered SAM alkyl chains. It should be noted, however, that the presence of organic contaminants on the bare silicon powder (see Experimental) may also contribute to trapping $\mathrm{HNO}_{3}$ on the uncoated substrate.

\section{B. Molecular dynamics simulations of interaction of gaseous HNO3 and water vapor with self-assembled monolayers}

In the prior study of Moussa et al., ${ }^{20}$ we modeled the potential energy interactions between the SAM substrate and the humid nitric acid vapor by introducing a Lennard-Jones 12-3 potential to act as an effective substrate. While this approach has been shown to accurately reproduce many properties of SAMs, a non-atomistic representation of the substrate limits the resolution of the interactions present when a molecule is in close proximity to the solid surface. As we have demonstrated previously in both experiment and simulation, nitric acid can reside deeply buried within the monolayer and in close proximity to the substrate. Here, we ensure that the local interactions that a buried molecule participates in are explicitly accounted for by modeling in atomistic detail both the substrate and the chemical structure of the head groups of the alkylsiloxanes.

In the present simulations, the nitric acid was found to preferentially reside inside the defect, taking less than $4 \mathrm{~ns}$ to both locate and embed within a defect in each of the three systems. In the $\mathrm{C} 8$, once the nitric acid penetrated the surface of the SAM, it continued unobstructed to the bottom of the defect site. In the mixed system the migration of nitric acid to the defect followed a two step process, wherein the nitric acid first breached the $\mathrm{C} 18$ surface and was transiently stabilized at the $\mathrm{C} 8$ level before breaching the $\mathrm{C} 8$ surface and continuing down to the substrate level. In the $\mathrm{C} 18$ system, the nitric acid initially penetrated the surface and was stabilized in a pocket of the SAM for several hundred picoseconds before continuing to migrate down to the substrate, with the entire event occurring in less than $1 \mathrm{~ns}$. In all systems, once embedded, the nitric acid remained in the defect for the full length of every subsequent simulation. Figure 5a, c, e shows the time-averaged density profiles of the nitric acid. The well-localized peak indicates that nitric acid resides buried within the SAM surface in each simulation for the duration of the trajectory. 
Inside the defect, the acid molecule is orientated with its proton pointed toward the substrate, forming a hydrogen bond with the hydroxyl of a defect-neighboring alkylsiloxane rather than the oxidized substrate, which is partially sterically obscured. Together with van der Waals interactions between the nitric acid and the alkylsiloxanes, the strong hydrogen bonding interaction stabilizes the nitric acid within the defect. Even in the largest water coverage simulation, where water uptake in the defects is sometimes observed, the nitric acid remained buried. Although we observe transient water uptake in the monolayer (see Fig. 5b, d), these waters interact only sparingly with the deeply buried nitric acid. Moreover, nitric acid exhibits a strong orientational bias resulting from the energetic benefit of donating a hydrogen bond to an oxygen of a hydroxyl group within the defect. This orientation prevents water from interacting directly with the acidic proton of the $\mathrm{HNO}_{3}$. Although the model of nitric acid does not permit dissociation, we can infer from the solvation environment of nitric acid that we observe in the simulations that $\mathrm{HNO}_{3}$ could be stabilized in molecular form within the defect. The orientation of $\mathrm{HNO}_{3}$ within the narrow cavity and lack of water within the defect suggests that nitric acid is unable to interact with the minimum number of waters needed to stabilize the contact ion pair. ${ }^{48-50}$ In a previous study, we observed a similar preferred orientation of $\mathrm{HNO}_{3}$ within a defected alkylthiolate SAM on a gold substrate ${ }^{20}$ There, the nitric acid was found to be stabilized in a defect in a dimer configuration with a tightly coordinated water molecule. Comparatively, the presence of the hydroxyls of the siloxanes in the present study seems to play an analogous role in orienting $\mathrm{HNO}_{3}$ within the defect. Figure 6 shows a representative snapshot of the nitric acid within the defect.

To study the ordering of the carbon chains of the monolayer, we computed the average second-order Legendre polynomial of the cosine of the angle between the $\mathrm{C}-\mathrm{H}$ bond vector and the z-axis, as a function of carbon number (shown in Figure 7). The $\mathrm{C} 8$ and $\mathrm{C} 18$ systems both show a relatively high degree of order throughout the alkyl chain, though the $\mathrm{C} 18$ monolayer is actually slightly less ordered than the C8 monolayer for all but the eighth carbon of the $\mathrm{C} 8$ chain. These results are consistent with our observation that nitric acid is able to intercalate between the chains of both systems, as both are similarly disordered. In the mixed system however, while the $\mathrm{C} 8$ molecules maintain a similar degree of order when compared to their pure counterpart, the $\mathrm{C} 18$ molecules show a drop in order beyond the $\mathrm{C} 8$ molecule. This reflects the fact that the last ten carbons of these molecules have greater conformational freedom because many of the neighboring chains are shorter. An example can be seen in Fig. 6, where the $\mathrm{C} 18$ molecules are observed to be very disordered at the SAM surface and obscure the $\mathrm{C} 8$ molecules from being exposed at the surface. We also computed order parameters as a function of water content, but were unable to resolve any significant dependence.

Summarizing the results of our simulations, we clearly see that nitric acid is able to intercalate between the hydrocarbon chains and reside within a pinhole defect of all three self-assembled monolayers, independent of the amount of water present. In all systems studied, once nitric acid was able to penetrate the monolayer, it remained buried for the duration of the simulation. Thus, we did not observe any significant differences in $\mathrm{HNO}_{3}$ uptake for monolayers differing in chain length. It is important to note that we used the same defect size and configuration in all of our simulations, which suggests that defect size and 
shape may play a more critical role than chain length for determining the uptake of nitric acid.

In summary, the combination of experiment and theory shows that gaseous $\mathrm{HNO}_{3}$ is taken up by SAMs, regardless of the length of alkyl chains and the degree of order/disorder of the film. This suggests that it is primarily defects in the SAM that are responsible for $\mathrm{HNO}_{3}$ uptake and shielding from water vapor, with these defects being common to all the SAMs studied. This is consistent with the results of vibrational sum frequency spectroscopy studies of the interaction of aqueous solutions with SAMs where small pinhole defects were thought to provide access of substrate surface sites to acids or bases in the solutions. ${ }^{51}$ When water vapor is added, the molecular $\mathrm{HNO}_{3}$ in the defects between the chains is shielded and thus does not fully dissociate, even up to quite high RH. The ions formed on dissociation recombine to generate molecular $\mathrm{HNO}_{3}$ when water is removed from the surface.

Assuming that organic films on surfaces in the boundary layer are irregular and less ordered than the SAMs studied here, undissociated molecular $\mathrm{HNO}_{3}$ may be present on surfaces in the boundary layer to a greater extent than previously appreciated. Recent studies of sea salt aerosol using vibrational sum frequency generation spectroscopy also show that the surface of the aerosol is rich in organics ${ }^{52}$ and disordered so small molecules can easily migrate from the top layer to within the organic layer. ${ }^{53} \mathrm{~A}$ related factor is the recently reported enhanced photochemistry for $\mathrm{HNO}_{3}$ on surfaces ${ }^{8,10-14}$ compared to that in the gas or aqueous phase. The combination of increased concentrations and enhanced photochemistry may make renoxification back to form gas phase nitrogen oxides more important than is currently included in atmospheric models. This could be particularly significant if nitrous acid (HONO) is formed by this photochemistry, since the photolysis of HONO is a major source of $\mathrm{OH}$ radicals in the troposphere. Indeed, the photolysis of nitric acid on leaf surfaces in a forest was recently proposed as a major source of HONO measured at a forested site. ${ }^{11}$

\section{Acknowledgments}

We are grateful for funding from the National Science Foundation (Grant no. 0909227). SAH was supported by an institutional cancer biology training grant (NIH/NCI T32CA009054). The molecular dynamics simulations and accompanying analysis were carried out on Greenplanet, which is supported by NSF grant CHE-0840513. MR gratefully acknowledges the support via the KONTAKT program of the Ministry of Education, Youth and Sports of the Czech Republic (grant ME09064). We would like to thank Dr. Mo Kebaili at Integrated Nanosystems Research Facility for producing the $\mathrm{SiO}_{\mathbf{X}}$ coating. We are grateful to Professor James N. Pitts Jr. for helpful discussions and comments on the manuscript.

\section{References}

1. Finlayson-Pitts, BJ.; Pitts, JN, Jr. Chemistry of the Upper and Lower Atmosphere. San Diego: Academic Press; 2000.

2. Schuttlefield J, Rubasinghege G, El-Maazawi M, Bone J, Grassian VH. J. Amer. Chem. Soc. 2008; 130:12210. [PubMed: 18722429]

3. Rubasinghege G, Grassian VH. J. Phys. Chem. A. 2009; 113:7818. [PubMed: 19534452]

4. Ndour M, Conchon P, D'Anna B, Ka O, George C. Geophys. Res. Lett. 2009; 36

5. Chen H, Navea JG, Young MA, Grassian VH. J. Phys. Chem. A. 2011; 115:490. [PubMed: 21210685]

6. Saliba NA, Yang H, Finlayson-Pitts BJ. J. Phys. Chem. A. 2001; 105:10339. 
7. Zhou XL, He Y, Huang G, Thornberry TD, Carroll MA, Bertman SB. Geophys. Res. Lett. 2002; 29

8. Zhou XL, Gao HL, He Y, Huang G, Bertman SB, Civerolo K, Schwab J. Geophys. Res. Lett. 2003; 30

9. Rivera-Figueroa AM, Sumner AL, Finlayson-Pitts BJ. Environ. Sci. Technol. 2003; 37:548. [PubMed: 12630471]

10. Handley SR, Clifford D, Donaldson DJ. Environ. Sci. Technol. 2007; 41:3898. [PubMed: 17612166]

11. Zhou XL, Zhang N, TerAvest M, Tang D, Hou J, Bertman S, Alaghmand M, Shepson PB, Carroll MA, Griffith S, Dusanter S, Stevens PS. Nature Geoscience. 2011; 4:440.

12. Baergen AM, Donaldson DJ. Environ. Sci. Technol. 2013; 47:815. [PubMed: 23237269]

13. Zhu CZ, Xiang B, Chu LT, Zhu L. J. Phys. Chem. A. 2010; 114:2561. [PubMed: 20121260]

14. Abida O, Du J, Zhu L. Chem. Phys. Lett. 2012; 534:77.

15. Law NL, Diamond ML. Chemosphere. 1998; 36:2607.

16. Lam B, Diamond ML, Simpson AJ, Makar PA, Truong J, Hernandez-Martinez NA. Atmos. Environ. 2005; 39:6578.

17. Simpson AJ, Lam B, Diamond ML, Donaldson DJ, Lefebvre BA, Moser AQ, Williams AJ, Larin NI, Kvasha MP. Chemosphere. 2006; 63:142. [PubMed: 16213561]

18. Gingrich SE, Diamond ML. Environ. Sci. Technol. 2001; 35:4031. [PubMed: 11686363]

19. Diamond ML, Gingrich SE, Fertuck K, McCarry BE, Stern GA, Billeck B, Grift B, Brooker D, Yager TD. Environ. Sci. Technol. 2000; 34:2900.

20. Moussa SG, Stern AC, Raff JD, Dilbeck CW, Tobias DJ, Finlayson-Pitts BJ. Phys. Chem. Chem. Phys. 2013; 15:448. [PubMed: 23160633]

21. Ulman A. Chem. Rev. 1996; 96:1533. [PubMed: 11848802]

22. Porter MD, Bright TB, Allara DL, D. Chidsey CE. J. Am. Chem. Soc. 1987; 109:3559.

23. Harrick, NJ. Internal Reflection Spectroscopy. John Wiley \& Sons, Inc.; New York: 1967.

24. Angst DL, Simmons GW. Langmuir. 1991; 7:2236.

25. Tillman N, Ulman A, Schildkraut JS, Penner TL. J. Am. Chem. Soc. 1988; 110:6136. [PubMed: 22148791]

26. Roeges, NPG. A guide to the complete interpretation of infrared spectra of organic structures. New York: Wiley; 1994.

27. Tichapondwa SM, Focke WW, Del Fabbro O, Muller E. Propellants Explos. Pyrotech. 2013; 38:48.

28. Gruvin BE, Johansson T, Hatcher ME. Mater. Sci. Eng. 1985; 71:363.

29. Karagulian F, Lea AS, Dilbeck CW, Finlayson-Pitts BJ. Phys. Chem. Chem. Phys. 2008; 10:528. [PubMed: 18183314]

30. Vogt R, Finlaysonpitts BJ. J. Phys. Chem. A. 1994; 98:3747.

31. Stevens MJ, Grest GS. Biointerphases. 2008; 3:FC13. [PubMed: 20408690]

32. Stevens MJ. Langmuir. 1999; 15:2773.

33. Szori M, Jedlovszky P, Roeselova M. Phys. Chem. Chem. Phys. 2010; 12:4604. [PubMed: 20428540]

34. Yeh I-C, Wallqvist A. J. Chem. Phys. 134

35. Mar W, Klein ML. Langmuir. 1994; 10:188.

36. Baaden M, Burgard M, Wipff G. J. Phys. Chem. B. 2001; 105:11131.

37. Jorgensen WL, Chandrasekhar J, Madura JD, Impey RW, Klein ML. J. Chem. Phys. 1983; 79:926.

38. Phillips JC, Braun R, Wang W, Gumbart J, Tajkhorshid E, Villa E, Chipot C, Skeel RD, Kale L, Schulten K. J. Comput. Chem. 2005; 26:1781. [PubMed: 16222654]

39. Moussa SG, McIntire TM, Szori M, Roeselova M, Tobias DJ, Grimm RL, Hemminger JC, Finlayson-Pitts BJ. J. Phys. Chem. A. 2009; 113:2060. [PubMed: 19173586]

40. McGraw GE, Bernitt DL, Hisatsun Ic. J. Chem. Phys. 1965; 42:237.

41. Querry MR, Tyler IL. J. Chem. Phys. 1980; 72:2495.

42. Goodman AL, Bernard ET, Grassian VH. J. Phys. Chem. A. 2001; 105:6443. 
43. Baltrusaitis J, Schuttlefield J, Jensen JH, Grassian VH. Phys. Chem. Chem. Phys. 2007; 9:4970. [PubMed: 17851593]

44. McCurdy PR, Hess WP, Xantheas SS. J. Phys. Chem. A. 2002; 106:7628.

45. Ritzhaupt G, Devlin JP. J. Chem. Phys. 1977; 81:521.

46. Ramazan KA, Wingen LM, Miller Y, Chaban GM, Gerber RB, Xantheas SS, Finlayson-Pitts BJ. J. Phys. Chem. A. 2006; 110:6886. [PubMed: 16722704]

47. Miller TM, Grassian VH. Geophys. Res. Lett. 1998; 25:3835.

48. Zhang X, Mereand EL, Castleman AW. J. Phys. Chem. 1994; 98:3554.

49. Kay BD, Hermann V, Castleman AW. Chem. Phys. Lett. 1981; 80:469.

50. Gilligan JJ, Castleman AW. J. Phys. Chem. A. 2001; 105:5601.

51. Hopkins AJ, McFearin CL, Richmond GL. Journal of Physical Chemistry C. 2011; 115:11192.

52. Ault AP, Zhao DF, Ebben CJ, Tauber MJ, Geiger FM, Prather KA, Grassian VH. Phys. Chem. Chem. Phys. 2013; 15:6206. [PubMed: 23463377]

53. Ebben CJ, Ault AP, Ruppel MJ, Ryder OS, Bertram TH, Grassian VH, Prather KA, Geiger FM. J. Phys. Chem. A. 2013; 117:6589. [PubMed: 23819692]

54. Dubowski Y, Vieceli J, Tobias DJ, Gomez A, Lin A, Nizkorodov SA, McIntire TM, FinlaysonPitts BJ. J. Phys. Chem. A. 2004; 108:10473.

55. Zhang Q, Archer LA. J. Phys. Chem. B. 2006; 110:4924. [PubMed: 16526732] 


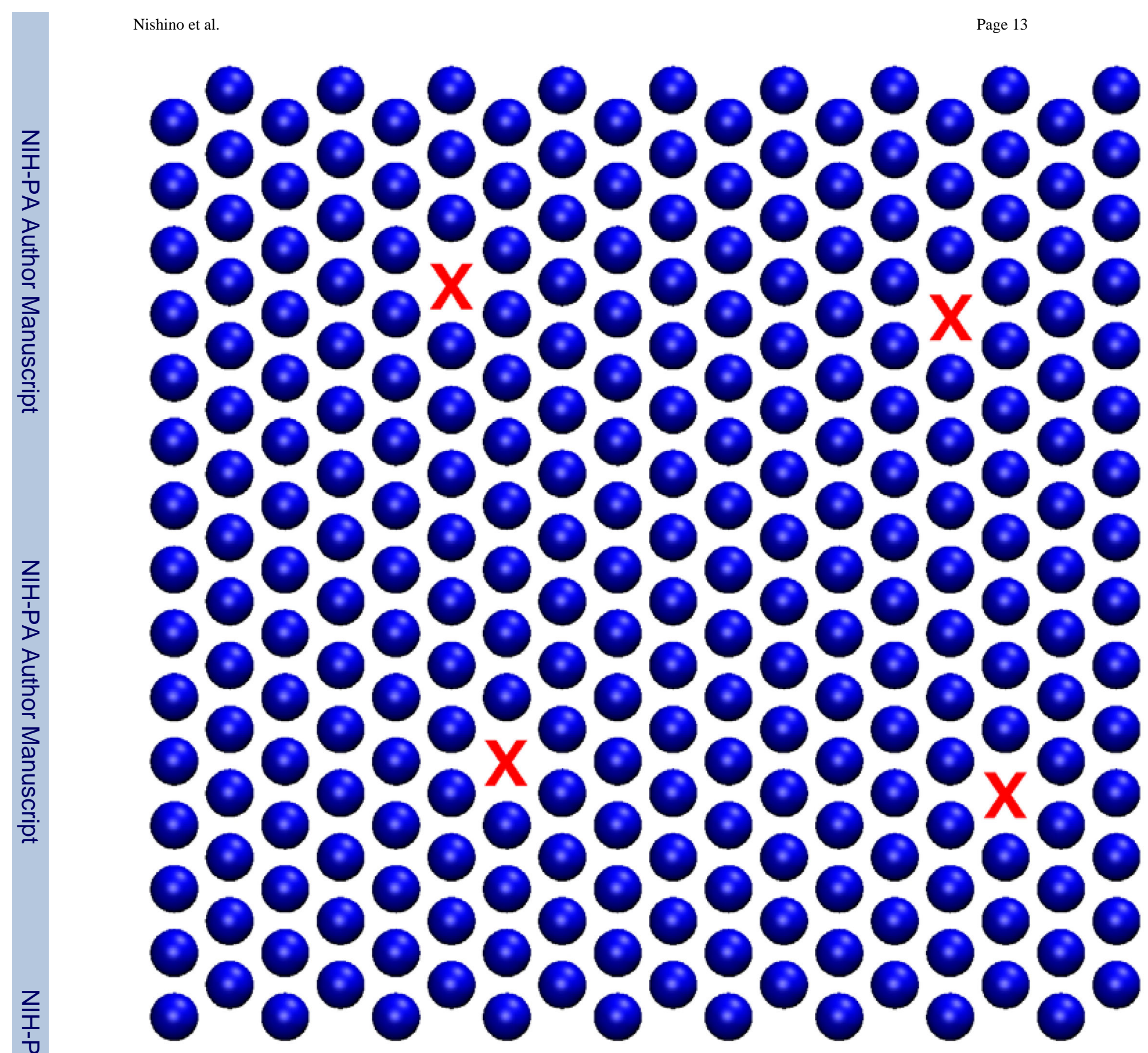

Figure 1.

System layout for MD simulations of the defective SAM surfaces. The defective SAM system is shown in a schematic fashion where the Si atoms of the SAM molecules are shown as blue spheres while the defects, where an alkylsiloxane chain has been removed and a hydroxyl group added in its place, are shown as a red "X." 
a. C18 SAM

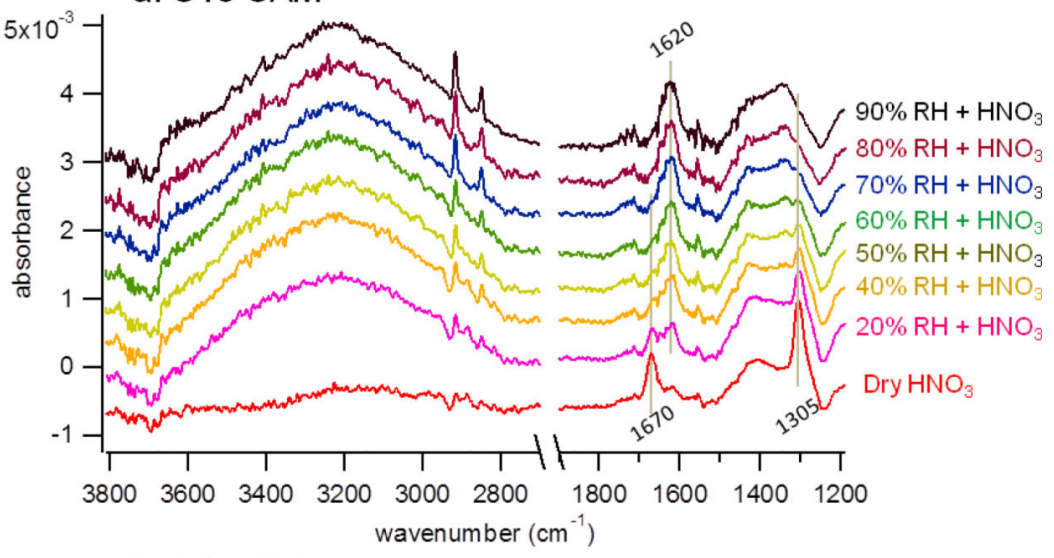

b. C8 SAM

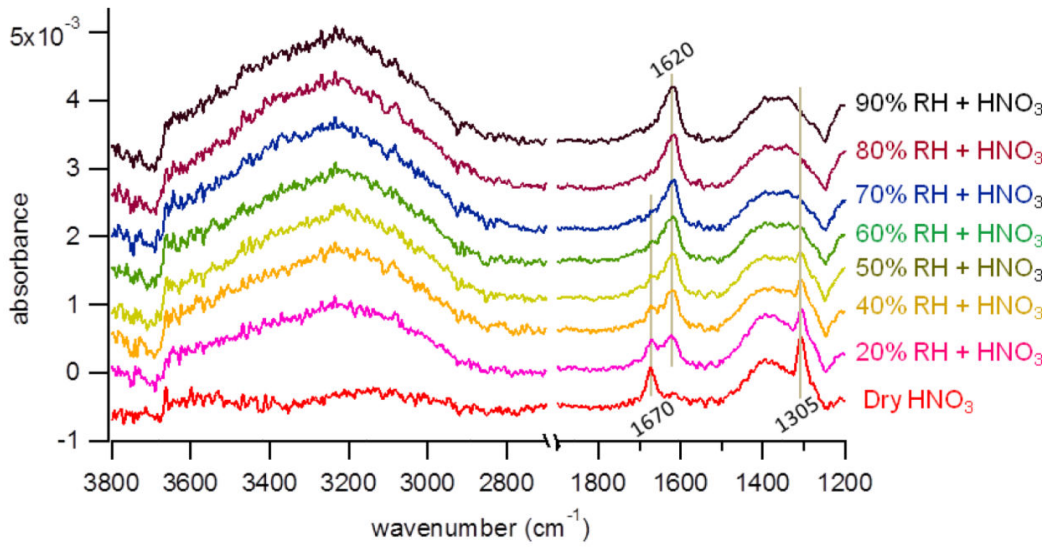

c. C8/C18 SAM

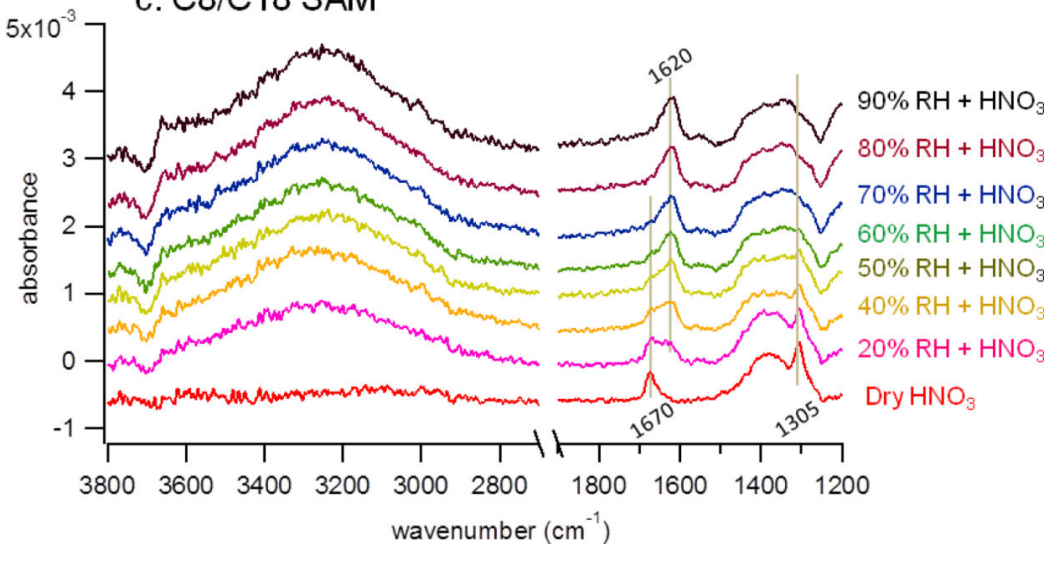

Figure 2.

ATR-FTIR absorption spectra of (a) C18 SAM, (b) C8 SAM and (c) C8/C18 mixed SAM that are exposed to dry $\mathrm{HNO}_{3}$ (red lines) followed by the incremental addition of water vapor (pink - brown lines). Spectra (A $\left.=\log S_{0} / S_{1}\right)$ are obtained by taking the ratio of the single beam spectrum where $\mathrm{SAM}$ is exposed to $\mathrm{HNO}_{3}$ before (red) and after (pink - brown) addition of water vapor at various $\mathrm{RH}\left(S_{1}\right)$ to that before the exposure to $\mathrm{HNO}_{3}$ and water vapor $\left(S_{0}\right)$. Spectra are offset from their normal baselines for clarity. 
a. C18 SAM

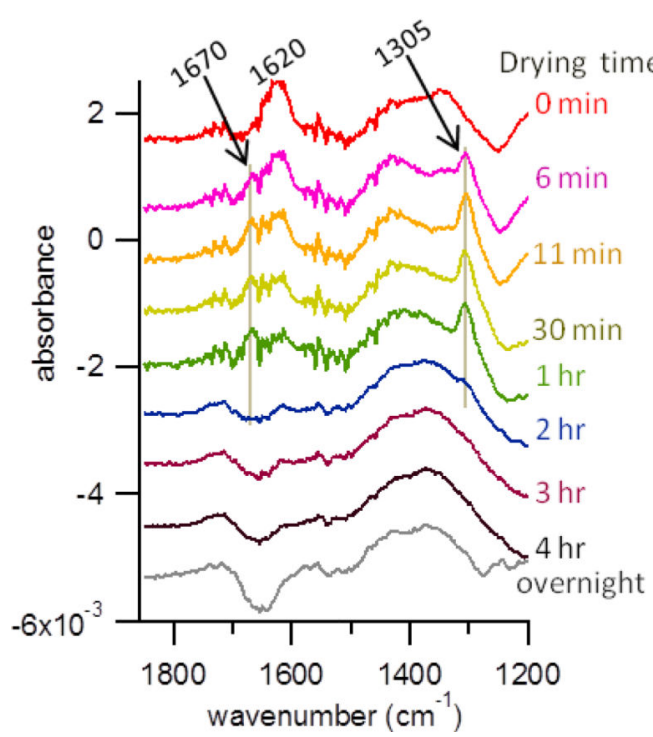

b. C8 SAM

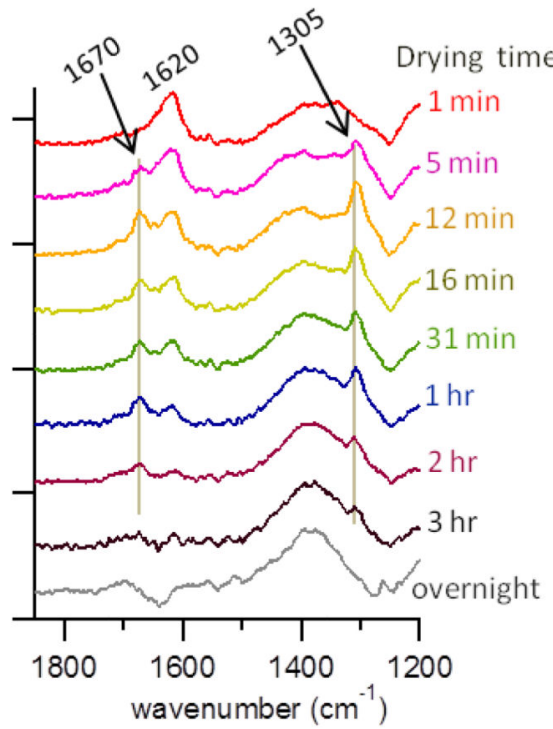

c. C8/C18 SAM

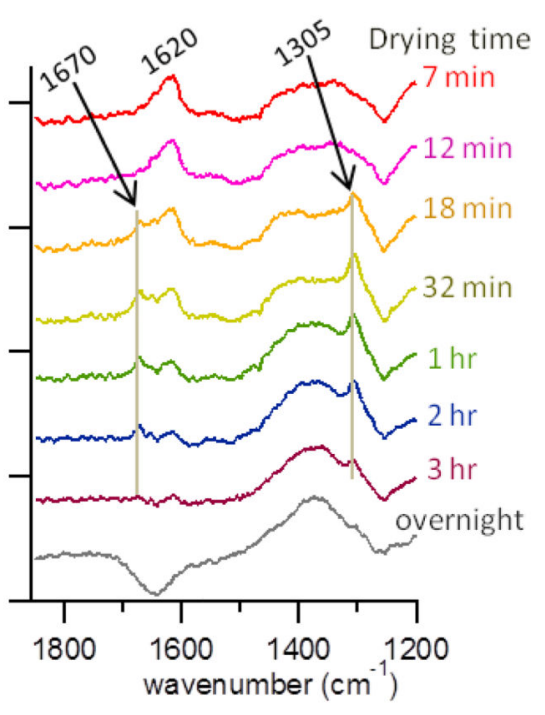

Figure 3.

ATR-FTIR absorption spectra of (a) C18 SAM, (b) C8 SAM and (c) C8/C18 mixed SAM dried with a flow of dry $\mathrm{N}_{2}$ after exposure to $\mathrm{HNO}_{3}(20-30 \mathrm{~min})$ and then adding water vapor up to $90 \% \mathrm{RH}$. Spectra $\left(\mathrm{A}=\log S_{0} / S_{1}\right)$ are obtained by taking the ratio of the single beam spectrum where $\mathrm{SAM}$ is exposed to $\mathrm{HNO}_{3}$ and water vapor and then to dry $\mathrm{N}_{2}\left(S_{1}\right)$ to that before exposure to $\mathrm{HNO}_{3}$ and water vapor $\left(S_{0}\right)$. Spectra are offset from their normal baselines for clarity. 
a. C18 SAM on Si powder

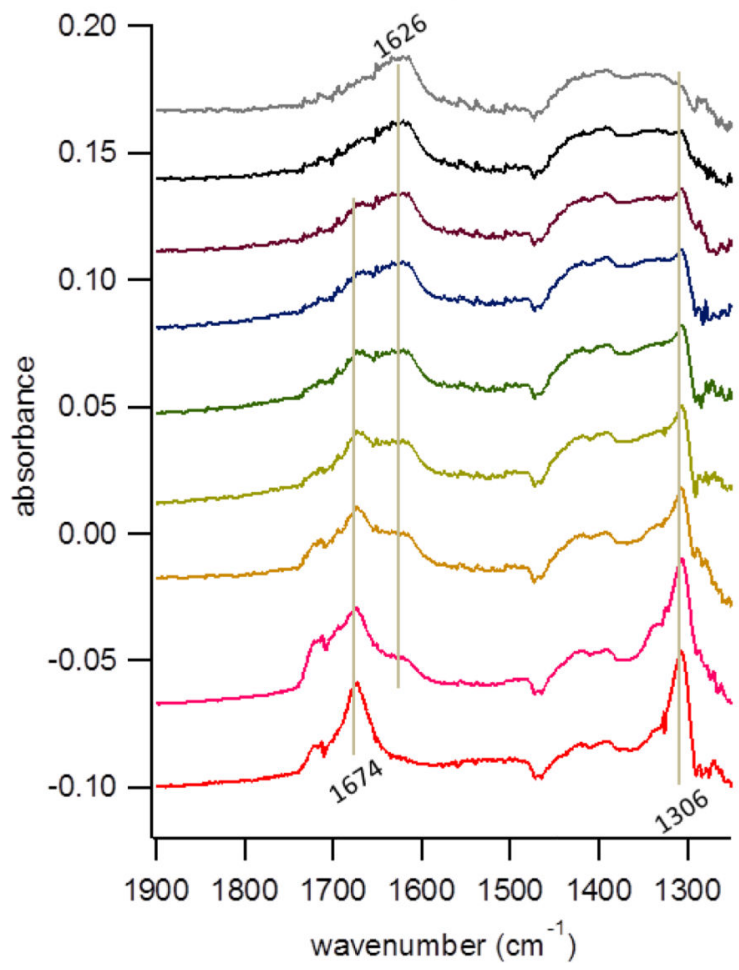

b. no SAM on Si powder

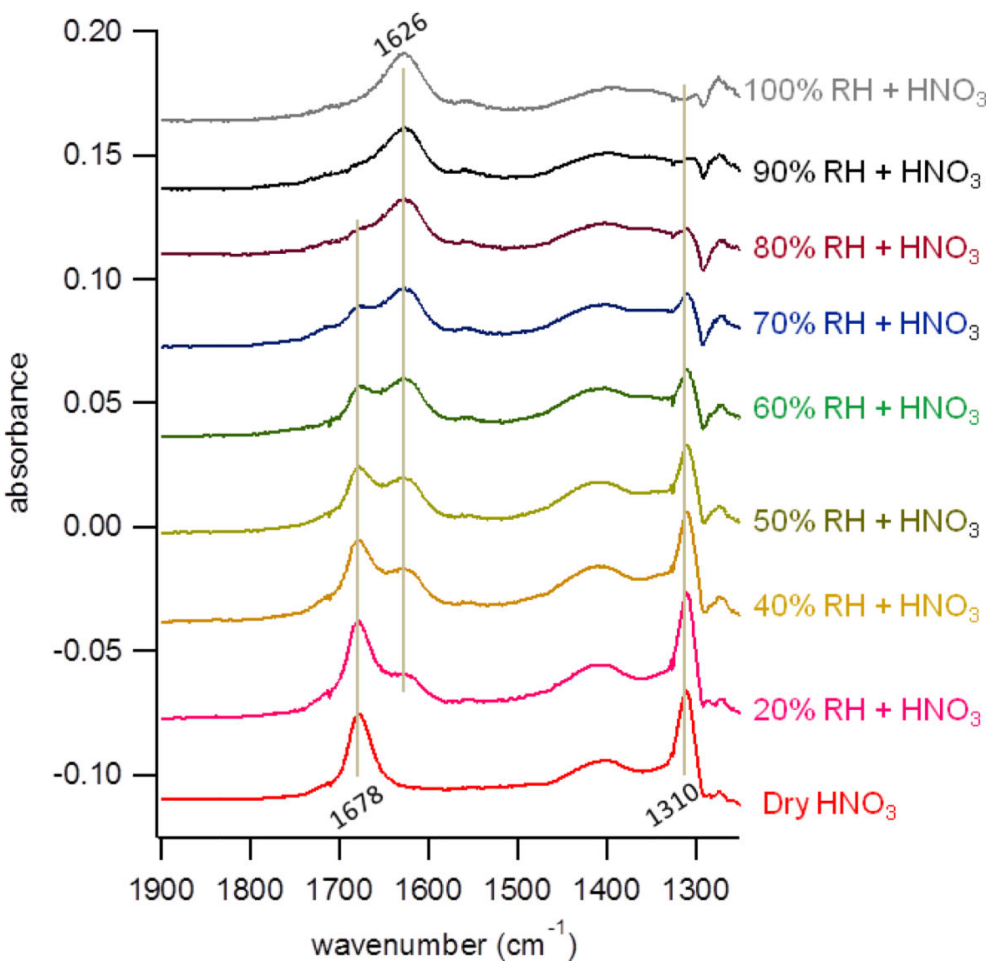

Figure 4.

DRIFTS spectra of Si powder (a) coated with C18 SAM and (b) without a SAM coating upon exposure to dry $\mathrm{HNO}_{3}$ (red lines) followed by the addition of increasing amounts of water vapor (pink - grey lines). Spectra $\left(\mathrm{A}=\log S_{0} / S_{1}\right)$ are obtained by taking the ratio of the single beam spectrum where the surface is exposed to $\mathrm{HNO}_{3}$ before (red) and after (pink - grey) addition of water vapor at various $\mathrm{RH}\left(S_{1}\right)$ to that before the exposure to $\mathrm{HNO}_{3}$ and water vapor $\left(S_{0}\right)$. Spectra are offset from their normal baselines for clarity. 

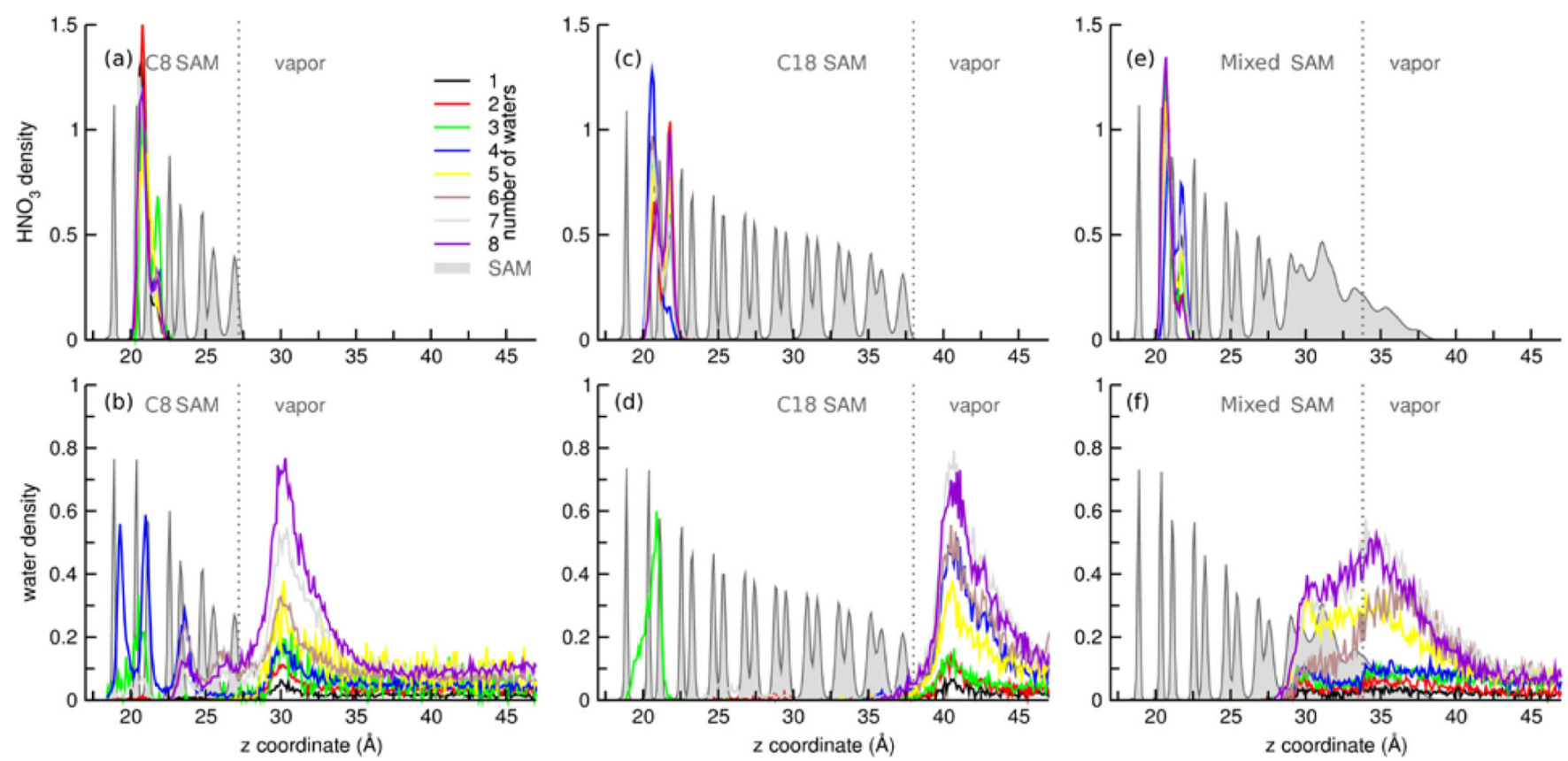

Figure 5.

Density profiles of nitric acid and water are shown in the upper and lower panels, respectively. The colors correspond to individual simulations with zero to eight water molecules in the simulated system. Density profiles were obtained from the final five nanoseconds of each simulation after $\mathrm{HNO}_{3}$ had been adsorbed and water added to the SAM. The density profiles of the SAM carbons are shown in gray for reference. The $\mathrm{HNO}_{3}$ and water profiles are normalized to the number of molecules in each simulation. SAM carbon profiles are arbitrarily scaled for reference. Nitric acid was found to reside buried in a defect, regardless of the amount of water included in the simulation, evidenced by the well-localized peaks in panels a, $\mathrm{c}$ and $\mathrm{e}$. 

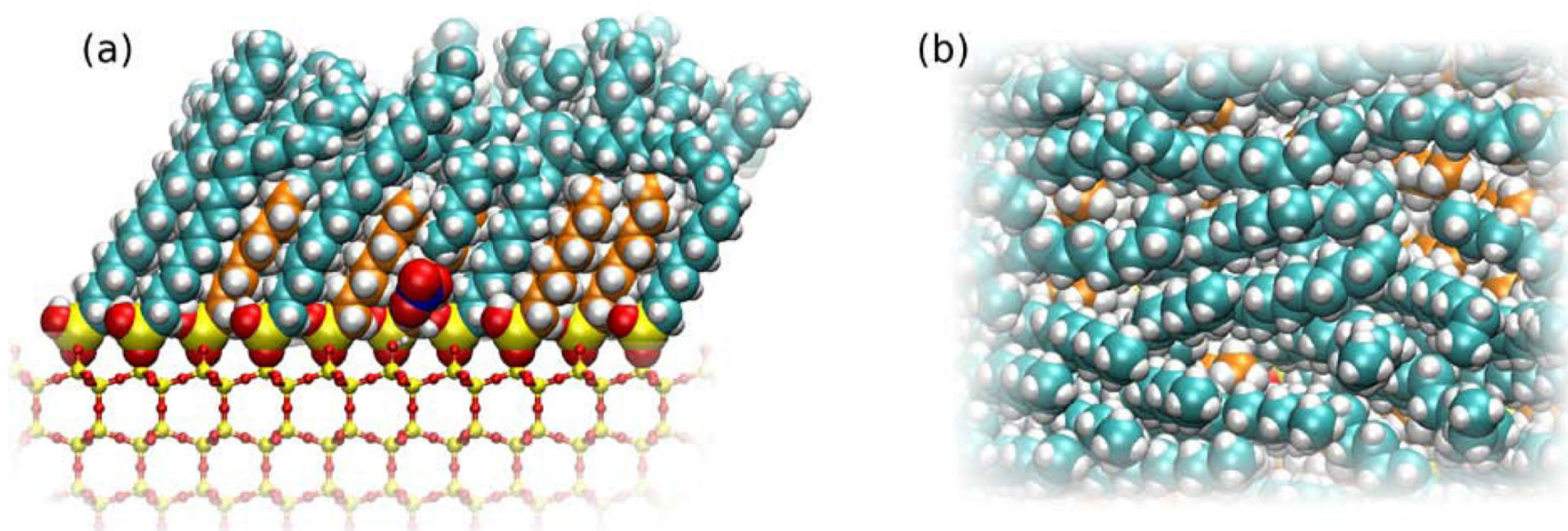

Figure 6.

Side (a) and top (b) views of the nitric acid embedded in the 1:1 C8/C18 mixture system with the molecules colored by their identity (cyan - $\mathrm{C} 18$, orange $-\mathrm{C} 8$ ). The interaction of the acidic proton of nitric acid and the terminal hydroxyl groups of the alkyl silanes stabilizes the buried nitric acid. In the configuration most often observed, a hydrogen bond is donated from nitric acid to a hydroxyl on the headgroup of a siloxane. This orientation prevents the acidic proton from interacting with water. The top view shows that nitric acid, which is positioned in the center of panel (b), is completely encapsulated within the defect and obscured from view. 


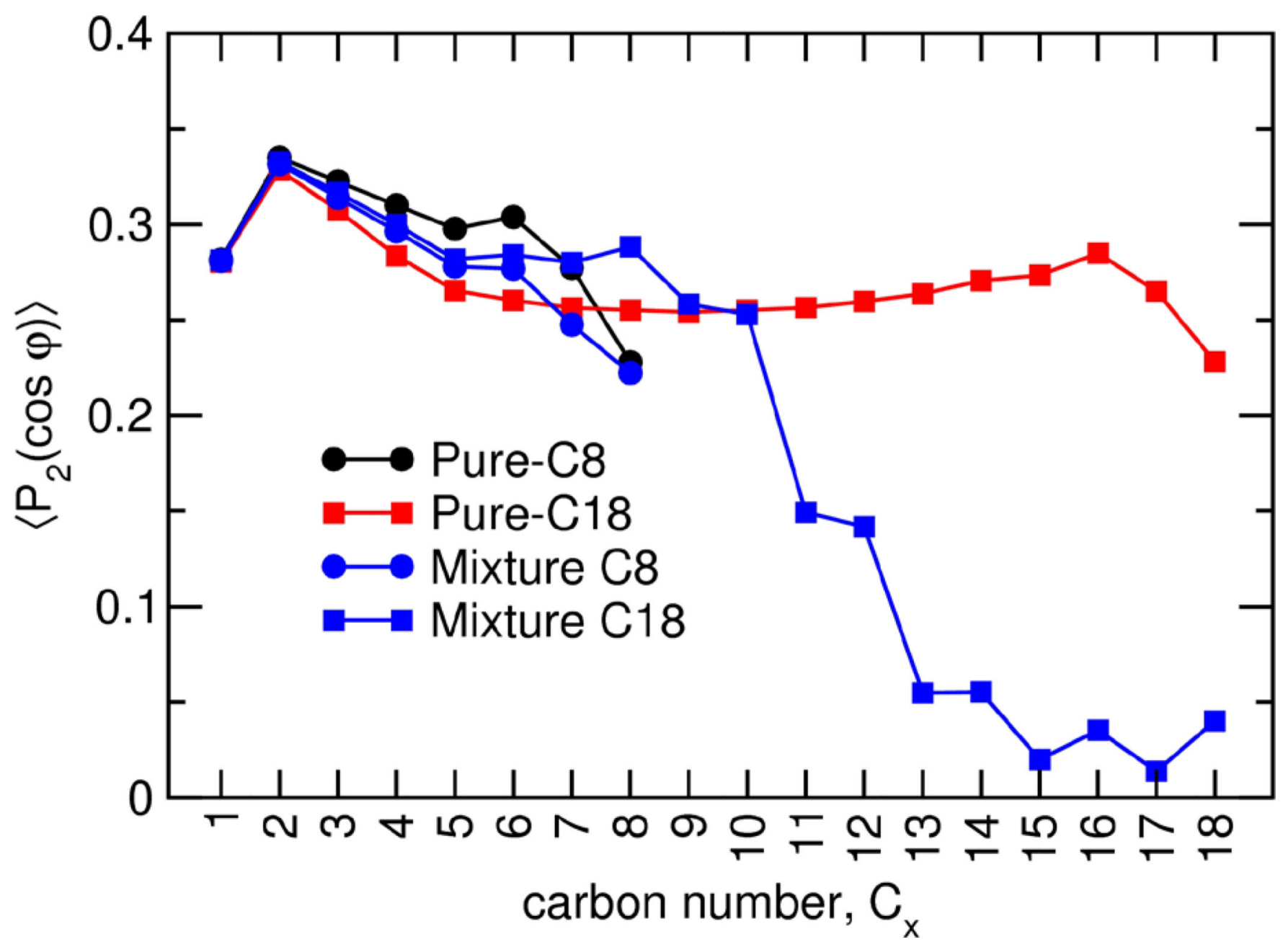

Figure 7.

Order parameters calculated for each simulated monolayer. Shown are averages of the $2^{\text {nd }}$ order Legendre polynomial of the cosine of the angle that each $\mathrm{C}-\mathrm{H}$ bond makes with the surface normal as a function of carbon number; higher values denote higher order. Data shown is from the simulations that contain four waters. The pure systems both show a high degree of order throughout the carbon backbone. In the mixed system, while the order of the $\mathrm{C} 8$ carbons are very similar to the pure $\mathrm{C} 8$ system, the order for the $\mathrm{C} 18$ chains drops once they have outgrown the $\mathrm{C} 8$ level. 
